\title{
The Principles and the Presumption of Equality
}

STEFAN GOSEPATH

A methodically well-grounded procedure is required if one wishes to proceed from basic moral premises to a theory of rights and justice. I wish to advocate the presumption of equality as a possible candidate for such a procedure. The presumption of equality is a prima facie principle of equal distribution for all goods that many scholars of political theory as well as public decision-makers/public opinion deem politically suitable for the process of public distribution. Applied to this domain, the presumption of equality requires that everyone, regardless of individual differences, should have an equal share in the distribution unless certain types of relevant differences justify, on universally acceptable grounds, unequal distribution. A strict principle of equal distribution is not required, but it is morally necessary to justify impartially any unequal distribution. Although this procedural principle is upheld by many scholars, albeit in different terms, one only rarely finds an explicit justification for it.

The aim of this paper is to offer such a justification in four steps. In section 8.1, the relation between the abstract concepts of justice and three well-known principles of equality - namely, (a) formal equality, (b) proportional equality, and (c) moral equality - and the relation between moral equality and social equality will be elaborated on. Section 8.2 introduces the presumption of equality as a necessary feature of any concrete conception of just treatment and distribution. Section 8.3 discusses and rejects different attempts to justify the presumption of equality. In section 8.4, finally, a substantive justification of the presumption of equality will be given that links the presumption back to the basic notions of justice and morals. 


\subsection{Principles of Equality}

Equality in its prescriptive usage has, of course, a close connection with morality and justice in general and distributive justice in particular. From antiquity onward, equality has been considered a constitutive feature of justice. Throughout history, emancipatory movements have used the language of justice to pillory existing social inequalities. But what exactly is the connection between equality and justice, i.e., what kind of role does equality play in a theory of justice?

Depending on which philosophical perspective one adopts, contrary answers may suggest themselves. Both equality and inequality are complex and multifaceted concepts. ${ }^{1}$ In any real historical context, it is clear that no single notion of equality can claim hegemony. ${ }^{2}$ Many egalitarians concede that much of our discussion of the concept is vague and abstract, but they believe that there is also a common underlying strain of important moral concerns implicit in it. ${ }^{3}$ Above all, the concept of equality serves to remind us of our common humanity, despite our various differences. From this point of view, then, equality appears, while not as one single principle, still as a one coherent idea that consists of a complex group of different principles. This is attested by the fact that, up to this day, philosophers have defended a variety of principles of equality, four of which will be mentioned in the following discussion.

Three well-known principles of equality seem today rather uncontroversial; namely, (a) formal equality, (b) proportional equality, and (c) moral equality. They will be quickly introduced in the following paragraphs to lay the foundations for the introduction and justification of a morth and much more controversial principle; namely, the presumption of equality.

(a) Formal Equality: when two persons have equal status in at least one normatively relevant respect, they must be treated equally with regard to this respect. This is the generally accepted formal equality principle that Aristotle formulated in reference to Plato: "treat like cases as like."4 Of course, the crucial question is which respects are normatively relevant and which are not. The formal postulate remains quite empty as long as it is unclear when or on the grounds of which features persons or cases should be considered equal. All

\footnotetext{
${ }^{1}$ See Larry Temkin, Inequality (Oxford: Oxford University Press, 1993), ch. 2.

${ }^{2}$ See Douglas W. Rae, Equalities (Cambridge: Harvard University Press, 1981), 132.

${ }^{3}$ See Bernard Williams, "The Idea of Equality," in Problems of the Self(Cambridge: Cambridge University Press, 1973), 230-249.

${ }^{4}$ Aristotle, Nicomachean Ethics, in The Complete Works of Aristotle, ed. Jonathan Barnes (Princeton: Princeton University Press, 1984), V.3. 1131a10-b15; Aristotle, Politics, in: ibid., III.9.1280 a8-15, III. 12. 1282b18-1282b23.
} 
debates over the proper conception of justice, i.e., over who is due what, can be understood as controversies over the question of which cases are equal and which are unequal. ${ }^{5}$ For this reason, equality theorists are correct in stressing that the claim that persons are owed equality becomes informative only when one is told what kind of equality they are owed. ${ }^{6}$

What is at stake here is a moral principle of justice, and with it the impartial and universalizable nature of moral judgments in general: for if the postulate of formal equality is morally acceptable, then more is required than simple consistency of the principle with one's subjective preferences. What is more important is its possible justification vis-à-vis others that are the potential subjects of the equal or unequal treatment in question-and this solely on the basis of the situation's objective features. That is, in order for the formal principle of equality to become a morally binding standard, one has to proceed from it to a more substantial, well-grounded principle of equality that can be justified to all persons concerned. One such substantialization of the principle of formal equality is the principle of proportional equality.

(b) Proportional Equality: according to Aristotle, there are two kinds of

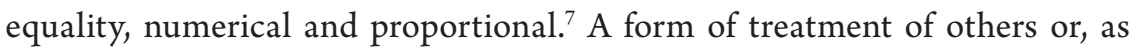
a result of it, a distribution is numerically equal when it treats all persons as indistinguishable, thus granting them the same quantity of a good, per capita. That is not always just. In contrast, a form of treatment of others or a distribution is proportional or relatively equal when it treats all relevant persons in relation to their due. Just numerical equality is, according to Aristotle, a special case of proportional equality: numerical equality is only just under special circumstances, viz. if persons are equal in distributionally relevant respects, then the corresponding proportions of the distributed goods must be equal too. Proportional equality specifies formal equality further; it is the more precise and detailed, hence, actually the more comprehensive formulation of what formal equality must entail in order to be morally acceptable. It indicates what produces an adequate equality: if factors speak for unequal treatment or distribution because the persons concerned are unequal in relevant respects, the treatment or distribution proportional to these factors is just. Unequal claims to treatment or distribution must be considered proportionally: this is the prerequisite for persons being considered equally in a just sense.

${ }^{5}$ Aristotle, Politics, $1282 \mathrm{~b} 22$.

${ }^{6}$ See Thomas Nagel, "Equality,” in Mortal Questions (Cambridge: Cambridge University Press, 1979), 106-127; Douglas W. Rae, Equalities (Cambridge: Harvard University Press, 1981); Amartya Sen, Inequality Reexamined (Oxford: Clarendon Press; Cambridge: Harvard University Press, 1992), 13.

${ }^{7}$ See Aristotle, Nicomachean Ethics, 1130b-1132b; Plato, Laws, in Complete Works, ed. John M. Cooper and D.S. Hutchinson (Indianapolis: Hackett, 1997), VI.757b-757c. 
(c) Moral Equality and Social Equality: even though the principle of proportional equality is a widely accepted standard of distributional justice nowadays, there is a minimal overlapping consensus among all leading schools of modern Western political and moral culture that some fundamental features of people may not be used to justify their unequal treatment and must thus be excluded from considerations of proportional distribution. ${ }^{8}$ More specifically, in spite of descriptive differences in certain relevant respects, all persons should be regarded and treated as moral equals, so that they are essentially entitled to the same basic moral rights and duties. The principle of treatment as an equal is not the same as equal treatment; it does not imply being entitled to an equal share, but being treated as a free and equal person. ${ }^{9}$ Following this assertion of the fundamental moral equality of all persons, different persons should be equal in their social status. This is the morally and politically fundamental principle of basic moral equality. As a moral ideal, it asserts that all people are of equal moral worth (or in other words: equal dignity) and that there are some claims that people are entitled to make on one another simply by virtue of their status as persons. ${ }^{10}$

Since "treatment as an equal" is an almost universally shared moral standard in contemporary theory, present-day philosophical debates are concerned with the kind of equal treatment is normatively required when we mutually consider ourselves persons with equal dignity. The principle of moral equality is too abstract and needs to be made concrete if we are to arrive at a clear moral standard. Nevertheless, no conception of just equality can be deduced from the notion of moral equality. Rather, we find competing philosophical conceptions of equal treatment serving as interpretations of moral equality. These need to be assessed according to their degree of fidelity to the deeper ideal of moral equality. ${ }^{11}$

From moral equality, one can derive a prohibition on arbitrary unequal treatment; that is, a prohibition on discrimination. Even if justice already implies that nobody should be arbitrarily put at a disadvantage, this

${ }^{8}$ See Gregory Vlastos, "Justice and Equality," in Social Justice, ed. Richard Brandt (Englewood Cliffs: Prentice-Hall, 1962), 31-72. This does not mean that this demand for the basic equality of all humans is in fact universally recognized; on the contrary, there are serious anti-egalitarian critics who argue against equality for different reasons. For a recent discussion see Uwe Steinhoff, ed., Basic Equality (Oxford University Press, forthcoming).

9 See John Rawls, Justice as Fairness. A Restatement (Cambridge: Harvard University Press, 2001), section 7, who prefers to speak of the "idea of free and equal persons."

${ }^{10}$ See Ronald Dworkin, Taking Rights Seriously (Cambridge: Harvard University Press, 1977), 179-183; esp. 277 and his well-known formulations "treating as equals" and "equal concern and respect" which, however, require further interpretation and elaboration.

${ }^{11}$ Will Kymlicka, Contemporary Political Philosophy (Oxford: Clarendon Press, 1990), 44. 
explication still leaves open which differences between persons are morally irrelevant and therefore should not be considered and which differences are to be considered. Moral equality does not completely fill in this variable, but it restricts it in an important respect. Different treatments of concerned parties based on differences in gender, race, social background, ethnicity, language, culture, religion or due to social hierarchies, etc., are morally arbitrary. This is because differences in natural endowments are differences for which the respective people are not themselves responsible, and therefore cannot justify different treatment. Otherwise the principle of moral equality would be violated. Thus primary discrimination (as one might call it) is excluded. Primary discrimination is to be understood as unequal treatment on the assumption of given differences of value between people that justifies allegedly different (often proportional) claims, whereas secondary discrimination is a differential treatment of persons who are regarded as morally equivalent. ${ }^{12}$ The purest form of the principle of primary discrimination is the norm that attributed character differences determines the value of a person and that the treatment or distribution has to follow this different value. ${ }^{13}$ In this sense, the principle of primary discrimination represents the opposite of the principle of moral equality. As such, primary discrimination includes all forms of oppression, whether people are subjected to exploitation, marginalization, powerlessness, cultural imperialism or violence ${ }^{14}$ Characteristic of the modern understanding of morality is that one can no longer believe in the possibility of a nonarbitrary, impartial justification of primary discrimination. This could refer only to metaphysical truths, which one can contest without being unreasonable. Moral equality follows negatively from the reasonable insight into the failure of all attempts at a nonarbitrary justification of primary discrimination. The struggle against primary discrimination of all kinds is and remains thus a classic egalitarian concern. It represents the heart of egalitarianism, which, despite general philosophical acceptance, has lost nothing of its political relevance. ${ }^{15}$

Through the prohibition and struggle against every form of primary discrimination, the claim of each person to be treated as morally equal should secure their fundamental, equal social and political status as equally

${ }^{12}$ See Ernst Tugendhat, Vorlesungen über Ethik (Frankfurt a.M.: Suhrkamp, 1993), 375-378.

${ }^{13}$ Ibid., chap. 3, esp. 47-51.

${ }^{14}$ See Iris Marion Young, Justice and the Politics of Difference (Princeton: Princeton University Press, 1990), ch. 2.

15 Those critics who criticize the more extensive distributive principles of modern egalitarianism also stress this, because egalitarianism no longer corresponds to its central concern, e.g., Iris Marion Young in Justice and the Politics of Difference (Princeton: Princeton University Press, 1990) and Elizabeth Anderson, "What Is the Point of Equality?" Ethics 109, no. 2 (1999): 287-337. 
legitimate members of society. These claims to social and political equality are thus also based on the acknowledgement of universal moral equality. They also exclude all unequal, hierarchical forms of social relationships by which some people dominate, exploit, marginalize, demean, and inflict violence on others: "As a social ideal, it holds that a human society must be conceived of as a cooperative arrangement among equals, each of whom enjoys the same social standing. As a political ideal, it highlights the claims that citizens are entitled to make on one another by virtue of their status as citizens, without any need for a moralized accounting of the details of their particular circumstances." 16

These aspects of political and social equality therefore fall under the principle of moral equality, but they do not exhaust it. Forms of secondary discrimination or differentiation are not excluded from moral, and in this respect, social equality, if they are compatible with the recognition of equal social status of concerned parties, as for example, differences according to merit, need, but also, if appropriate, according to race, gender, and background, as in cases of affirmative action or fair punishment. "Where there is social equality, people feel that each member of the community enjoys an equal standing with all the rest that overrides their unequal ratings along particular dimensions." ${ }^{17}$ The upshot is that moral equality requires social and political equality but leaves open the question whether other dimensions such as e.g., a person's natural talents, creativity, intelligence, innovative skills or entrepreneurial ability can be the basis for legitimate inequalities. ${ }^{18}$ This fact should make it already clear that claims to social and political equality, as justified as they are, can never exhaust all justified entitlement to justice and equality in the social and political sphere. Thus, even

\footnotetext{
${ }^{16}$ Samuel Scheffler, "What is Egalitarianism?" Philosophy \& Public Affairs 31, no. 1 (2003): 22 and Samuel Scheffler, "Choice, Circumstances and the Value of Equality," Politics, Philosophy \& Economics 4, no. 1 (2005): 5-28.

${ }^{17}$ David Miller, “Equality and Justice," Ratio 10, no. 3 (1997): 232. Miller regards social equality as a value distinct from justice, as does Jonathan Wolff, "Fairness, Respect, and the Egalitarian Ethos,” Philosophy \& Public Affairs 27, no. 2 (1998): 97-122. For examples of views that draw both on justice and on a value of social equality distinct from justice, see Thomas Scanlon, “The Diversity of Objections to Inequality," in The Lindley Lecture, Lawrence: University of Kansas (1996) and Martin O’Neill, "What Should Egalitarians Believe?” Philosophy \& Public Affairs 36, no. 2 (2008): 119-156.

${ }^{18}$ That these are forms of illegitimate inequalities is the claim of so-called "luck-egalitarians" e.g., Ronald Dworkin, "What Is Equality? Part 2: Equality of Resources," Philosophy \& Public Affairs 10, no. 4 (1981): 283-345; Richard Arneson, "Equality and Equality of Opportunity for Welfare,” in Equality: Selected Readings, ed. Louis Pojman and Robert Westmoreland (New York: Oxford University Press, 1997), 229-241 and G. A. Cohen, "On the Currency of Egalitarian Justice," Ethics 99, no. 4 (1989): 906-944.
} 
if one sees social justice in a society as analogous to friendship or marriage as a relationship of equals ${ }^{19}$ (as unrealistic as that might be), the question of which kinds of secondary discrimination or specification are required by justice is still left entirely open.

To determine any morally appropriate conduct requires more than a reference to equal social status or standing. This is important because in order to adjudicate a claim to a legitimate equal or legitimate unequal standing to others in society, one first of all needs a comparative standard. Secondly, one needs a certain conception of what an equal standing in society amounts to and implies in terms of rights and goods. Since forms of oppression and domination, e.g., marginalization, status hierarchy, domination, exploitation, and disrespect, are seldom self-evident, the question arises about the legitimacy and justification of such claims. Recourse must be made to a theory of morality and justice, which by means of a justification procedure is able to assess claims as appropriate or inappropriate. For justice is concerned with which claims about what things (i.e., treatment or goods) are to be justified vis-à-vis whom on what grounds. Imperatives of justice always have to do with fair treatments and shares, which can be determined only in procedures of justification.

This requirement of universal and reciprocal justification is linked to the morality of equal respect in that this morality demands that each individual becomes equally considered in every instance of justification and distribution. This principle states that norms can be regarded as justified if, and only if, free and equal persons, who wish to regulate their co-existence by means of such norms, are rationally able to agree on the norms in question. ${ }^{20}$ Since it is immoral to force someone to do something of which he or she does not approve, only reasons acceptable to the other person can give one the moral right to treat this person in a specific way. According to the principle of moral equality, two people regard each other as equals if each accepts the obligation to justify their actions by principles acceptable to the other, and in which they take mutual consultation, reciprocation, and recognition for granted. Equal consideration is thus accorded to all persons and their interests. Equal

${ }^{19}$ For such a view, see: Scheffler, "What is egalitarianism?" 22.

${ }^{20}$ For such views, see Immanuel Kant, Groundwork on the Metaphysics of Morals (Cambridge: Cambridge University Press, [1785] 1997); John Rawls, A Theory of Justice, 2nd ed. (Cambridge: Harvard University Press, [1971] 1999); Thomas Scanlon, What We Owe to Each Other (Cambridge: Harvard University Press, 1998), esp. ch. 5; Jürgen Habermas, Moral Consciousness and Communicative Action (Cambridge, MA: MIT Press, 1990); Bruce Ackerman, Social Justice in the Liberal State (New Haven: Yale University Press, 1980), esp. ch. I.; Rainer Forst, The Right to Justification: Elements of a Constructivist Theory of Justice (New York: Columbia University Press, 2011). 
respect, which we reciprocally owe to one another, thus requires respect for the autonomous decisions of each noninterchangeable individual. The core of the value of equality is a normative conception of human relations. This normative conception sees the autonomy of each individual as the standard of justification for general rules, norms, rights, etc. To treat persons as equals and to grant them social and political equality amounts to granting them a right to justification.

With these clarifications and specifications of moral equality, it should be clear that "equal" or "equal measure" in the context of moral equality is in no way "purely formal" or "empty" or "redundant" — as alleged by critics. ${ }^{21}$ Here, rather, it refers to the independence of moral justification from all power relations and primary discriminations. This principle excludes certain differences, such as first- and second-class citizens, as morally unjustified. It allows only those differences that are determined by means of justification procedures to be in principle acceptable by all. "Equal" and "equal measure" have therefore an essential function in this principle.

\subsection{Introducing the Presumption}

In order for moral equality to become more concrete than moral, social and political equality and for it to be applicable, one has to proceed from these ideals to an even more concrete principle of equality. Thus, the questions that remain to be answered are the following: first, which kind of equal treatment or distribution is normatively required if we reciprocally regard each other as persons of equal dignity and of equal social and political standing? Otherwise it would remain unclear what moral equality and social justice as social relationships of equals demand in terms of treatment and distribution. Thus we have to know: by means of which procedural principle shall we construct a substantial conception of just treatment and distribution from the abstract premise of "moral equality"? Once we have adopted such a procedural principle, the second problem that needs to be solved is: according to which criteria shall we apply it; that is, what are the normatively relevant criteria that shall decide the equal or unequal treatment of individuals and distribution of resources to them?

${ }^{21}$ See H.L.A. Hart, “Between Utility and Rights,” Columbia Law Review 79, no. 5 (1979): fn. 42; Robert Goodin, Political Theory and Public Policy (Chicago: Chicago University Press, 1982), 89f; Charles Larmore, Patterns of Moral Complexity (Cambridge: Cambridge University Press, 1987), 6; Joseph Raz, The Morality of Freedom (Oxford: Oxford University Press, 1986), chap. 9.; J. R. Lucas, “Against Equality,” Philosophy 40, no. 154 (1965): 296-307. 
At first sight, the answer to the question, i.e., which kind of distribution is normatively required under the premise of moral equality, seems clear. Insofar as one can generally and reciprocally justify certain differences among individuals - beyond their equal dignity-as being relevant in terms of treatment and distribution, it is imperative that they be treated proportionally to those differences. Proportional equality is thus the principle of formal equality.

To give an example, children and adults should, according to this principle, normally partake of different amounts of calories in order to satisfy their equal claim to adequate and sufficient nutrition. The adequate allocation of calories then is a case of proportional equality. Adults and children are treated unequally in terms of what they receive (namely, unequal amounts of calories) but are treated equally in terms of their claim to adequate nutrition. Reasons for an unequal distribution are proportionally accounted for; this is the precondition for the consideration of everyone as equal. Therefore, consideration and a fortiori treatment as equals means equal treatment in proportion but not in result.

If we assume that there is no persuasive alternative to proportional equality, because the known alternatives - such as market-based liberal theories of property, needs-based theories, aggregate theories that are egalitarian only in an instrumental sense (such as utilitarianism), or a theory of complete, strict, numerical equal treatment-seem implausible and unjust for a number of reasons, then we must determine those criteria that are capable of justifying equality or inequality of people in terms of treatment and distribution. ${ }^{22}$ Once we know which (descriptive) features are morally relevant, it is neither necessary nor even possible to stipulate a primacy of (quantitatively or numerically) equal distribution anymore, for it is those criteria that then determine the mode of distribution in the first place.

However, the question of how we shall proceed in those cases where we do not have relevant criteria at our disposal or where no relevant differences can be found remains to be answered. Thus, we are looking for a secondary principle that is the default option if the primary principle of distributive justice, i.e., proportional equality, is not applicable.

\footnotetext{
${ }^{22}$ This is actually a core debate among social egalitarians. However, the criteria for a justified unequal distribution need not be discussed here. The following arguments still work independently of which relevant criteria will turn out to be justified. More on the justification of these criteria can be found in Stefan Gosepath, Gleiche Gerechtigkeit. Grundlagen eines liberalen Egalitarismus (Frankfurt a. M.: Suhrkamp, 2004), ch. V.
} 
It is precisely here, I submit, that the procedural principle of the presumption of equality takes effect. ${ }^{23}$ This is a prima facie principle of equal distribution for all distributable social goods: ${ }^{24}$

\begin{abstract}
Everyone must be treated numerically or strictly equally irrespective of their descriptive differences, unless certain (types) of difference(s) are presently relevant and successfully justify, through generally acceptable reasons, unequal treatment or unequal distribution.
\end{abstract}

${ }^{23}$ This approach is not uncommon. To name the most prominent proponents: Henry Sidgwick speaks in The Methods of Ethics (London: Macmillan, 1874), 380 of onus probandi (burden of proof). Hugo Bedau (in "Egalitarianism and the Idea of Equality," in Equality (Nomos IX), ed. J. Roland Pennock and John Chapman (New York: Atherton Press, 1967), 3-27 and Gosepath (in Gleiche Gerechtigkeit, ch. II.8) call this postulate of equality the 'presumption for equality.' Stanley Benn and Richard Peters speak in their influential discussion in Social Principles and the Democratic State (London: Allen \& Unwin, 1959), 111 of a "presumption against inequality." Bernard Williams calls it in "The Idea of Equality," in Problems of the Self (Cambridge: Cambridge University Press, 1973), 230-249 the 'relevant reasons approach'; Richard Hare in Freedom and Reason (Oxford: Clarendon Press, 1963), 118 the 'corollary of the requirement of universality'; Ernst Tugendhat in Dialog in Leticia (Frankfurt a.M.: Suhrkamp, 1997), ch. III the 'postulate of symmetry' (Symmetriesatz); Wilfried Hinsch in Gerechtfertigte Ungleichheiten. Grundsätze sozialer Gerechtigkeit (Berlin/New York: de Gruyter, 2002) the 'default option.” See also Derek E. Browne, "The Presumption of Equality," The Australasian Journal of Philosophy 53, no. 1 (1975): 46-53; Peter Westen, Speaking of Equality (Princeton: Princeton University Press, 1990), $230 \mathrm{ff}$.

${ }^{24}$ Here, it is resources construed as all-purpose goods that constitute the object of distribution. "Resources" (or "goods") is a general term that encompasses material goods (money, jobs, property), social goods (chances, privileges, prestige), and political goods (rights, authority, liberties). The term chosen is deliberately broad because it can then subsume everything that a society deems valuable, attributable, and a potential object of a just distribution. Rights, liberties, chances, self-respect, and human dignity are goods in a broader sense, goods that we value and would like to possess. Of course they are a special type of goods and differ from goods of consumption. Rights, liberties, and chances do not simply exist as natural goods. Rather, they are created through the organization of our social existence. They are created when a society regulates the distribution of other goods. This means that both in the case of material goods and when it comes to rights and opportunities, we regulate moral entitlements; that is, entitlements detailing which goods, rights, and opportunities one can legitimately expect and how one may use them. Also, the question of which rights and duties ought to be accorded to whom is resolved in the same way as the question of the distribution of goods. The principles of distributive justice that determine who is entitled to what, when, and according to which principle determine the claims that citizens ought to mutually accord one another from a moral point of view. In this way, they establish moral rights and the corresponding duties. Providing a justification for (specific) rights is nothing other than intersubjectively justifying a distribution of certain types of goods as something that one must mutually accord to one another as a consequence of a mutual recognition as equals. 
The example of the distribution of a cake is frequently used in this context and shows how obvious this principle is: ${ }^{25}$ a parent wishes to share a cake among his or her children-how should he or she do this if we assume that all children would like their slice to be as large as possible? If no child can advance a convincing reason why his or her slice should be larger than everyone else's, then the cake must be divided into equally large pieces. Or-to use an often cited example in the discussion on the equality of distribution ${ }^{26}$ - how should the crew of a ship that has landed on a desert island distribute the local resources? Relevant reasons for an unequal distribution would be, for example: needs, acquired rights, merit, and maximizing utility.

The presumption accords a primacy to equal distribution only in terms of formal reasoning. Unequal distribution requires justification; equal distribution does not. In principle, this is compatible with every form of inequality insofar as it can be justified. However, it allocates the burden of proof in a way that makes it more difficult to justify inequalities. We find a similar presumption effective in criminal proceedings: as long as doubts about the relevant facts persist, i.e., as long as a case has not been proven to the judge, a criminal sentence may not be imposed (in dubio pro reo). ${ }^{27}$ Here, too, the burden of proof lies with the one who seeks to justify an unequal treatment (in this case, a specific judicial sentence): it is not that the accused must prove his innocence, but that the state or prosecutor must prove his guilt. This principle is analogous to the presumption of equality.

\subsection{Different Accounts of the Presumption}

So how does one explain that numerically equal distribution has priority and why must the onus probandi lie with the proponents of unequal distribution? To begin with, one must grant the critics that the presumption of equality, whenever it is mentioned in the pertaining literature and discussions at all, is rarely argued for. ${ }^{28}$ Some authors hold that this presumption can be inferred from the

${ }^{25}$ See Isaiah Berlin, "Equality as an Ideal," Proceedings of the Aristotelian Society 61 (195556): 301-326, at 305; Ernst Tugendhat, Vorlesungen über Ethik (Frankfurt a.M.: Suhrkamp, 1993), 373 f.; id., Dialog in Leticia, 69; id., "Gleichheit und Universalität in der Moral," in id., Moralbegründung und Gerechtigkeit, ed. Marcus Willaschek (Münster: Lit, 1997), 11.

${ }^{26}$ See Dworkin, "What is Equality? Part 2: Equality of Resources."

${ }^{27}$ The 'in dubio'-postulate is mainly referred to as a judicial specification of the presumption of innocence, which in turn is deduced in different ways from and thus founded on constitutional norms, such as the rule of law, basic rights, and human dignity.

${ }^{28}$ Exceptions are Ernst Tugendhat in Vorlesungen über Ethik, $373 \mathrm{f}$. and Dialog in Leticia, ch. III, esp. 68, who must be given credit for being one of the few who developed a normative argumentation for the presumption of equality, and Wilfried Hinsch, "Angemessene Gleichheit," in Modelle politischer Philosophie, ed. Rolf Geiger, Jean-Christophe Merle and Nico Scarano 
formal equality postulate that stipulates that "like cases be treated alike." ${ }^{29}$ From this, they argue, it should follow that all individuals must be treated equally as long as no reasons for an unequal treatment can be found. But the presumption of equality can in fact not be immediately deduced from the formal equality postulate: the mere absence of specific reasons for unequal distribution cannot ipso facto ground a claim to universalization. Otherwise, this would imply that the relevant situations in question have already been identified as being equal in a normatively relevant sense. But what is it that should be treated equally in the first place? There are situations in which we do not even know which cases can count as being equal. I venture that the presumption of equality ought to be applied even when it has not yet been determined whether all cases to be considered for distribution are equal in a prescriptive sense. Therefore, the formal equality postulate does not contain the presumption of equality. Similarly, the presumption cannot be deduced from proportional equality, for this contains a prescription only for cases that are nonequal. The presumption of equality, by contrast, applies to cases where no relevant reasons either for equality or inequality in treatment can be identified.

More frequently, it is argued that we know the presumption to be valid by intuition. Often the above mentioned example of the cake is then used as a kind of circumstantial evidence-equal distribution should evidently follow simply because there is no specific reason that justifies unequal distribution. But if we rely on our intuitions to confirm a normative principle, we must ask ourselves where, in turn, this intuition stems from, and whether there are any other plausible explanations at hand. For example, with reference to the cake-case, it is not clear (to say it again) why equal distribution should follow simply from the fact that reasons for unequal distribution are absent-one might also argue, for instance, that it is the children's positive claim to their parent's equal care and respect that grounds an imperative of numerically equal distribution.

Moreover, the appeal to the presumption's intuitive plausibility often seems to operate by way of exclusion: if there are (ex hypothesi) no reasons for one particular kind of unequal distribution, then what, many people argue, would be left but the option of equal distribution? It seems, then, that for them, equal distribution is the default setting, as it were, unless a case can be made for

(Paderborn: Mentis, 2003), 260-271. According to Tugendhat, justifying morals, generally speaking, means justifying it to all. The concept of justification is, to him, thus more basic than moral principles and already contains a reference to equality. For a critique of Tugendhats argument, see the essays in Markus Willaschek (ed.), Ernst Tugendhat. Moralbegründung und Gerechtigkeit (Münster: Lit, 1997).

${ }^{29}$ For a review of the relevant literature and critique see Westen, Speaking of Equality, 233, esp. fn. 8 . 
reasonable exceptions. But this reasoning precludes alternative possibilities for filling this vacuum. For it must be taken into account that those in favor of unequal distribution do not, as a rule, attribute an intrinsic value to inequality. ${ }^{30}$ Instead, they refer to a rule with a specific content, usually along the lines of the meritocratic idea that distribution should reflect individual achievement. Therefore, it is - as we shall see shortly-very well possible to think of reasonable, well-grounded justifications for an unequal distribution even in those cases where an immediate reason for unequal distribution is lacking: the just solution to situations such as these does not necessarily have to be numerical equality.

And this would in fact not be inconsistent with the presumption, insofar as the latter includes the possibility of there being material reasons for unequal distribution: ${ }^{31}$ if one counter-factually assumed that all distributable goods were always distributed completely according to criteria such as needs, merit, and other differential criteria, and if one further assumed that these criteria were universally acceptable as a justification for unequal distribution, the presumption would indeed never become effective. It could be compatible with a highly stratified pattern of distribution. It is only because, empirically, it is very unlikely that all distributable goods are always distributed completely along justified criteria such as needs, merit, and so on, that there is normally space for the presumption to come into play.

In order to gauge arguments for and against the presumption of equality, we must thus posit such a situation where criteria for a justified inequality either do not apply or, if they do, still leave some goods that remain to be distributed. If this is assumed, certain goods must be left over for whose equal or unequal

\footnotetext{
${ }^{30}$ Such a position, which to my knowledge nobody has ever put forward, must fail for the same reasons as a position that ascribes equality an intrinsic value. Intrinsic egalitarians regard equality as desirable even if the equalization would be of no use to any of the affected parties-e.g., when equality can only be produced through depressing the level of everyone's life. But something can only have an intrinsic value when it is good for at least one person, i.e., makes one life better in some way or another. The well-known "leveling-down" objection indicates that doing away with inequality in fact ought to produce better circumstances - it would otherwise be unclear why equality should be desired. (For such an objection see Robert Nozick, Anarchy, State, and Utopia (New York: Basic Books, 1974), 229; Joseph Raz, The Morality of Freedom (Oxford: Oxford University Press, 1986), ch. 9, 227, 235; Larry Temkin, Inequality (Oxford: Oxford University Press, 1993), 247-248.).

${ }^{31}$ Whether merit constitutes a justified reason is subject to debate and may, at this stage of our argument, remain undecided because this question cannot help us to arbitrate between the presumption and possible alternatives. Many contemporary theories of justice consider merit, however, a morally arbitrary criterion for distribution (cf. John Rawls, A Theory of Justice, 2nd ed. (Cambridge: Harvard University Press [1971], 1999), 64 f., 87 f.; cf. Gosepath, Gleiche Gerechtigkeit, ch. V. I. 2.f).
} 
distribution no convincing material reasons can be found. Only in this situation can the presumption be put to the test. Thus, the presumption of equality does not apply, in the first place, as an alternative option to certain material reasons of-equal or unequal-distribution but only, in the second place, as a default option if these material reasons do not allow for a complete (equal or unequal) justified distribution for all goods.

Why-this is thus the follow-up question that needs to be asked now should numerical equality be the standard for distribution in situations where there are no reasons for inequality but positive reasons for an equal distribution of goods are similarly lacking? After all, one could think, prima vista, of three not implausible alternatives to this presumption of equality. (1) Where positive reasons in favor of equality or inequality are absent, all possible ways of distribution (including equal distribution) assume an equal (or indifferent) standing, and thus all would be equally acceptable. (2) In this case of moral indifference, another possibility would be to randomize the outcome so that in the last resort not all possibilities of distribution would be equally acceptable but (with an indifferent starting position) only that kind of distribution that owes its existence to a random factor. A variant of this idea is the notion of the protection of acquired possession: ${ }^{32}$ property is often defended on the grounds of the historical or "natural" character of its distribution; for example, in the case of a country's natural resources or because the free market produces, through mechanisms of supply and demand, a certain allocation of goods that the current possessors then claim to be theirs. ${ }^{33}$ (3) A third alternative would be to refrain from a distribution of goods for as long as no positive reasons for equality or inequality can be put forward until a reasonable case can be made for redistribution. In a world where all goods have already been distributed, this option also results in the protection of acquired possessions; all goods then remain the property of their former possessors. If the existing factual relations of property cannot be justified on their own grounds (and if they could, this would mean that, contrary to the original premise, positive

\footnotetext{
32 The protection of possession is, in my experience, one of the most commonly used criteria of "distribution."

${ }^{33}$ This inequality cannot ex hypothesi be defended on the grounds of individual attributes (such as merit or need), but at most on the grounds that the natural or social processes which have resulted in the distributional pattern in question can — for identifiable reasons-be considered as justified. See Nozick, Anarchy, State, and Utopia. If Nozick's argumentation were successful, the justified, historically evolved patterns of distributions could be regarded as well-founded exceptions from the presumption of equality. However, I agree with many critiques of Nozick. See, for example, Will Kymlicka, Contemporary Political Philosophy, 2nd ed. (Oxford: Oxford University Press, 2001), ch. 4.
} 
arguments for that distribution do exist), then again we would end up with a historically contingent allocation.

All in all, it thus seems that the different variants of the idea to randomize distribution present a serious alternative to the presumption of equality. If, however, historical evolution of distribution or simple randomization are seen as substantial acceptable reasons for unequal distribution-e.g., when they are considered as "God's will" - then they are no longer alternatives to the presumption but must be examined as possible candidates for justified inequalities within the presumption's framework: they would then apply for as long as it is possible to identify a certain pattern of distribution as "truly random" or "truly historically evolved;" in cases where it is impossible to decide which distribution fulfills this requirement, however, the presumption of equality could still be used as a standard of action or decision. ${ }^{34}$ An argument in favor of the presumption, such as I now wish to present, must thus exclude random distribution as an alternative principle of distribution - but it need not do more (e.g., refute random distribution per se as a form of justified inequality).

\subsection{A Substantive Justification in Favor of the Presumption}

The argument in favor of the presumption of equality, I propose, can be obtained from two premises whose plausibility is largely accepted and that are closely connected to the abstract notions of justice and moral equality as they have been introduced in the beginning of this paper. The first premise (which will be referred to as the "principle of adequacy") follows from the explication of the concept of justice and maintains that justice requires the adequate, impartial and formally equal consideration of everyone's moral and legal claims. It is generally agreed that the meaning of justice is that an action is just if, as a result, everybody is given what they are entitled to. By definition then, every kind of justice is based on entitlement and appropriateness. Arbitrariness would violate the principle of adequacy. From the point of view of justice, every situation may only be judged on the basis of those objective features that are relevant for an adequate consideration of an individual's moral rights. That which cannot be justified as just can, from a normative point of view, no longer

\footnotetext{
${ }^{34}$ In some situations, principles of historical priority (such as 'first come, first served' or standing in line) and fair lottery (such as the flipping of a coin) may indeed provide the best standard of procedure, especially if the goods to be distributed are not divisible in a way that would allow every interested person to receive a share and thus a method must be found that grants everybody the same chance of receiving the desired good.
} 
be sustained. The second premise is the requirement of justification and stems from the explication of the principle of moral equality or equal human dignity or from the principle that people should be treated as equals. Norms can be regarded as justified if, and only if, free and equal persons, who wish to regulate their co-existence by means of such norms, are rationally able to agree on the norms in question. The principle of justification specifies what constitutes a good justification of the adequacy of a situation or action; namely, only that kind of justification that takes the interests of all those concerned into equal consideration. The principle of justification thus determines in which respect a situation or action is adequate.

The presumption, I submit, follows from the two premises in the following way: since every person must be able to claim for himself all advantages, and in particular, all goods in his possession on the grounds of reciprocal and general reasons, together, the principle of justification and the equal consideration of all subjective (moral or legal) claims require a justification for situations that can in principle be changed. A situation that can be changed is subject to the claim of justice; that is to say, its justice or injustice must be established by means of the principle of justification and be corrected as necessary. The equal and adequate consideration of all subjective claims demands that suum cuique-each have his own. A different allocation of goods can only be justified on the grounds of relevant differences among all those concerned. Only such differences that are relevant in terms of distribution can justify unequal treatment as adequate to each and every person. An unequal distribution without such justification would be arbitrary. Justice, however, requires the exclusion of all arbitrariness. Thus where no relevant differences exist (either because no one can stake a justified claim to certain goods in the first place or because all demands have been satisfied), everyone must receive the same amount of goods. ${ }^{35}$

In public distribution, anyone who lays claim to more than an equal share owes all others an adequate universal and reciprocal justification. If this cannot be provided, i.e., if there is no reason for unequal distribution that can be universally and reciprocally justified to all, ${ }^{36}$ then equal distribution is the

\footnotetext{
${ }^{35}$ This is not a pragmatist justification of the presumption. A pragmatist justification is, however, presented by Edna Ullmann-Margalit in "On Presumption," Journal of Philosophy 80, no. 3 (1983), 143-162, esp. 155, who argues for the presumption as a means to overcome a stalemate in a practical deliberation. Louis Katzner argues in "Presumptions of Reason and Presumptions of Justice," Journal of Philosophy 70, no. 4 (1973), 89-100 and "Presumptivist and Nonpresumptivist Principles of Formal Justice," Ethics 81, no. 3 (1971), 253-258 that the presumption is only justifiable on the grounds that it will lead to the least damage to all.

${ }^{36}$ This is based on the assumption that all are, by and large, equal in the relevant sense; otherwise, their apparent differences in the relevant sense would provide reasons for unequal treatment or distribution.
} 
only legitimate principle of distribution. How could it be otherwise? Any unequal distribution would mean that someone receives less, and another more. Whoever receives less can justifiably demand a reason for being disadvantaged. Yet there is ex hypothesi no such justification. Hence, any unequal distribution is illegitimate in this case. If no convincing reasons for unequal distribution can be brought forward, the only option remaining is that of equal distribution. Equal distribution is therefore not merely one alternative among many, but rather the inevitable starting point that must be assumed insofar as one takes the justificatory claims of all to be of equal weight.

Does the presumption really follow from the two premises? ${ }_{5}^{37}$ Possibly, one could accept the argument that we are often in possession of something or that we have certain general advantages that we cannot justify generally and reciprocally. But, one could critically object, why does it follow from there that this possession or advantage should be given away? Thus the problem remains of how to deal with morally indifferent possessions or advantages for which no justification can be given. Again we are faced with the preservation of historically contingent distribution or the principle of random choice as possible alternatives to the presumption.

Having presented the argument in favor of the presumption of equality, however, we can now show why these apparent alternatives are not, in fact, solutions: it is because the presumption follows from the justification requirement. The justification requirement morally applies to all possibilities of distribution. If one assumes ex hypothesi that there are no good reasons for an unequal distribution, then random distribution is no justifiable alternative to the presumption; it violates the principle of adequacy. If goods are distributed at random, differences will result that cannot be justified on grounds of individual differences between persons. The distribution does not do justice to those concerned, even if the unequal treatment is not an expression of an (unjustified) explicit rejection of the principles of equality. Every person may demand justification as to why he or she should have been assigned less by lot than another person, and why he or she should accept this. Thus, random choice is not universally justifiable as a distribution procedure. ${ }^{38}$

From the first premise, moreover, one can extract an additional second one: namely, that we may only speak of a condition as being just if we can

\footnotetext{
${ }^{37}$ On the argumentation against the presumption, see Thomas Schramme, "Die Anmaßung der Gleichheitsvoraussetzung," Deutsche Zeitschrift für Philosophie 51, no. 2 (2003), 255-275; Harry Frankfurt, “Equality as a Moral Ideal,” Ethics 98, no. 1 (1987), 21-42.

${ }^{38}$ Unless the persons concerned have intersubjectively agreed in some cases to distribute by allotment on a random basis and thus this distribution is justified.
} 
conceive of all distributable goods as being distributed according to the principles of justice. Already existing distributions must be justifiable on the grounds of the well-known consideration that, in a hypothetical situation, they would have come about in just this way, i.e., by an adequate consideration of the individuals' moral rights. Every other conceivable distribution (random or already existing) does not as such take into account the individuals' moral claims. Thus, random choice, again, does not fulfill the condition of adequacy. Conditions that are inadequate, not justifiable, and therefore unjust are morally in need of correction, as can be inferred from the aforesaid first premise based on the concept of justice. This is why the objection mentioned ('I may not have a justified claim to my possessions but why should anyone else have one?') fails. If the principle of justification is not fulfilled, then the requirement of justice is consequently violated, too, as not everyone is considered as equal. We are confronted with an unjustified and therefore unjust condition that can and must be converted into a just one. Thus any kind of random choice is excluded (unless it operates within the framework of the presumption as a candidate for justified inequalities).

In situations such as these, where universally acceptable reasons for both equal and unequal distribution are lacking, only the presumption of equality fulfills the adequacy condition because it treats equal cases equally. If none of the concerned persons can lay claim to a relevant difference, then all cases are, in this respect, prima facie equal and must be treated equally in order to be treated adequately and justly. This is why, according to this reasoning, a society may take away a person's unjustified advantage or property and equally distribute it among its members.

This is the argument for the presumption. ${ }^{39}$ It demonstrates that equal distribution is not merely one alternative among many, but rather the inevitable starting point that must be assumed insofar as one takes the justificatory claims of all to be of equal weight.

The argument has also shown, however, that the presumption is not independent of a substantive moral conception of what a just distribution entails: it explains the significance of equality as a default option while simultaneously clarifying the very meaning of equality.

The presumption of equality provides an elegant procedure for constructing a theory of distributive justice. The following questions would have to be answered in order to arrive at a substantial and full principle of justice. What goods and burdens are to be justly distributed (or should be distributed)?

\footnotetext{
${ }^{39}$ For this argumentation, see Gosepath, Gleiche Gerechtigkeit. A comparable argumentation can be found to my knowledge only in Hinsch, "Angemessene Gleichheit."
} 
Which social goods comprise the object of distributive justice? What are the spheres (of justice) into which these resources have to be grouped? Who are the recipients of distribution? Who has a prima facie claim to a fair share? What are the commonly cited, yet in reality; unjustified exceptions to equal distribution? Which inequalities are justified? Which approach, conception or theory of egalitarian distributive justice is therefore the best? How such a theory of justice will look is another matter. ${ }^{40}$

${ }^{40}$ I developed such a theory in Gosepath, Gleiche Gerechtigkeit. 